\title{
Resilience to Loss and Chronic Grief: A Prospective Study From Preloss to 18-Months Postloss
}

\author{
George A. Bonanno \\ Teachers College, Columbia University
}

\author{
Darrin R. Lehman, Roger G. Tweed, and \\ Michelle Haring \\ University of British Columbia
}

\author{
Camille B. Wortman \\ State University of New York at Stony Brook
John Sonnega, Deborah Carr, and Randolph M. Nesse
University of Michigan, Ann Arbor

\begin{abstract}
The vast majority of bereavement research is conducted after a loss has occurred. Thus, knowledge of the divergent trajectories of grieving or their antecedent predictors is lacking. This study gathered prospective data on 205 individuals several years prior to the death of their spouse and at 6- and 18-months postloss. Five core bereavement patterns were identified: common grief, chronic grief, chronic depression, improvement during bereavement, and resilience. Common grief was relatively infrequent, and the resilient pattern most frequent. The authors tested key hypotheses in the literature pertaining to chronic grief and resilience by identifying the preloss predictors of each pattern. Chronic grief was associated with preloss dependency and resilience with preloss acceptance of death and belief in a just world.
\end{abstract}

The death of a spouse is generally assumed to be one of the most stressful experiences that people encounter during the course of their lives (Holmes \& Rahe, 1967). However, there are marked individual differences in how much and for how long people grieve (Bonanno \& Kaltman, 1999, 2001; Wortman \& Silver, $1989,2001)$. In addition to what is assumed to be the typical or common reaction, an initial increase in depression that gradually subsides over time, several other patterns of grief have been discussed in the literature. These include prolonged or chronic grieving, the noticeable absence of grief symptoms, and delayed grief responses. Social and personality psychologists have become increasingly interested in these different trajectories, and how they compare with those observed for other marital transitions and other stressful life events (e.g., Brennan \& Shaver, 1998; Diener, Gohm, Suh, \& Oishi, 2000; Frederick \& Loewenstein, 1999; Harvey \& Miller, 1998; Pillow, Zautra, \& Sandler, 1996). Unfortunately, because of the methodological and conceptual limits of most bereavement research, there remains a dearth of understanding about variations in grief outcome. With few exceptions (e.g., Levy, Martinkowski, \& Derby, 1994; Middleton, Burnett, Raphael, \&

George A. Bonanno, Department of Counseling and Clinical Psychology, Teachers College, Columbia University; Camille B. Wortman, Department of Psychology, State University of New York at Stony Brook; Darrin R. Lehman, Roger G. Tweed, and Michelle Haring, Department of Psychology, University of British Columbia, Vancouver, British Columbia, Canada; John Sonnega, Deborah Carr, and Randolph M. Nesse, Department of Psychology, University of Michigan, Ann Arbor.

The research described in this article was supported by National Institute on Aging Grants R01-AG610757 and R01-AG15948-01A1 awarded to Camille B. Wortman and Randolph M. Nesse, respectively.

Correspondence concerning this article should be addressed to George A. Bonanno, Department of Counseling and Clinical Psychology, 525 West 120th Street, Teachers College, Box 218, Columbia University, New York, New York 10027. E-mail: gab38@columbia.edu
Martinek, 1996), bereavement studies have examined adjustment by aggregating data across respondents, making it impossible to determine what percentage of respondents follow different trajectories over time. Moreover, virtually none of the studies that have provided data about divergent patterns of reaction to loss have included preloss data.

This is problematic for two reasons. First, as we demonstrate below, some patterns of grief reaction are not possible to detect without preloss data. Second, the absence of prospective data complicates efforts to identify the various factors that might explain divergent reactions to the loss, and help adjudicate among the many hypotheses offered in the literature. For example, although prior psychopathology appears to be an important predictor of chronic grief reactions (e.g., Kim \& Jacobs, 1991; Zisook \& Shuchter, 1991), no study has yet distinguished chronic grief reactions from preexisting chronic depression. At the opposite extreme, bereavement theorists have tended to view the absence of distress as a form of denial or grief inhibition (Middleton, Moylan, Raphael, Burnett, \& Martinek, 1993), or as an indication of lack of attachment to the spouse (Fraley \& Shaver, 1999; M. J. Horowitz, 1990). The possibility that the absence of distress following interpersonal loss might be indicative of resilience has rarely been considered (Bonanno, Papa, \& O'Neill, in press). Yet, it is well established that considerable numbers of individuals show little or no distress following interpersonal loss (Bonanno \& Kaltman, 2001). No study has attempted either to identify a group of individuals with stable low distress prior to and after a loss, or to examine the prebereavement characteristics of such individuals. Evidence that the absence of distress during bereavement is indicative of resilience would forge links with recent research on resilience in both early (Luthar \& Cicchetti, 2001) and later human development (Wallace, Bisconti, \& Bergeman, 2001), and in response to different types of life stress (Bonanno, Field, Kovacevic, \& Kaltman, 2002; Waysman, Schwarzwald, \& Solomon, 2002). 
In this article, we attempt to address the aforementioned methodological and conceptual issues. In contrast to most bereavement research, the data for the current study were obtained from a sample of conjugally bereaved adults prior to the death of their spouse and again 6 and 18 months after the death. First, we sought to operationally define chronic grief and resilience and to distinguish these patterns from other related patterns of reaction to loss. Next, we sought to evaluate a number of contemporary hypotheses about the antecedents of chronic grief and the absence of grief by identifying preloss predictors (e.g., personality, qualities of the relationship) of these patterns.

\section{Identifying Divergent Reactions to Conjugal Loss}

No previous studies have been designed specifically to examine whether bereaved individuals exhibit different patterns of distress following the loss of a spouse. However, we are aware of six studies, conducted over the past 3 decades, that provide data relevant to this issue (Bonanno \& Field, 2001; Bonanno, Keltner, Holen, \& Horowitz, 1995; Bournstein, Clayton, Halikas, Maurice \& Robins, 1973; Lund et al., 1985-1986; Vachon, Rogers, et al., 1982; Vachon, Sheldon, et al., 1982; Zisook \& Shuchter, 1986). These studies assessed depression or other forms of distress in the early months following the death of the spouse, and then again anywhere from 13 to 60 months after the loss.

\section{Chronic Grief}

Across most bereavement studies, estimates of enduring or chronic depression and distress have ranged from $10 \%$ to $20 \%$ (for reviews, see Bonanno \& Kaltman, 2001; Jacobs, 1993). However, the lack of prebereavement data in these studies leaves unanswered many important questions about the nature of chronic grief. As noted previously, one such question involves the relationship between chronic grief and preexisting psychopathology. If a person displays consistently elevated levels of depression following the death of a spouse, how can we determine whether this represents an intense and prolonged grief reaction, or whether it merely reflects preexisting psychopathology? The possible role of prior emotional difficulties in grief reaction is further clouded by the fact that most of the studies supporting this association have measured preloss depression using retrospective accounts obtained during bereavement (e.g., Nuss \& Zubenko, 1992; Parkes \& Weiss, 1983; Zisook \& Shuchter, 1991). Such an approach is vulnerable to depression-related memory biases that may inflate the relationship between current and prior difficulties (Clark \& Teasdale, 1982; Elliot \& Greene, 1992; Hirschfeld et al., 1989). It is well established that depressed individuals tend to overestimate both the intensity (Schrader, Davis, Stefanovic, \& Christie, 1990) and the number (Zimmerman \& Coryell, 1986) of previous symptoms of depression. Bereaved individuals suffering from chronic grief or depression may similarly overestimate their prior emotional difficulties. Indeed, this was recently demonstrated in a study of memory for previous grief over a 5-year period. Even though most of the conjugally bereaved individuals in this study had relatively low levels of grief-related distress by the 5-year point of bereavement, current distress still proved to be as good or better a predictor of participants' memory for distress during the beginning months of bereavement as the actual level of previous distress (Safer, Bonanno, \& Field, 2001).
A handful of studies have measured depression both before and after the loss of a spouse. Most (e.g., Bass, Bowman, \& Noelker, 1991; Norris \& Murrell, 1990), but not all (e.g., Folkman, Chesney, Collette, Bocellari, \& Cooke, 1996), of these studies have found a positive relationship between pre- and postbereavement depression. Together, these findings suggest that it is critically important to distinguish chronic depression from chronic grief reactions, and that such a distinction be made using actual preloss data rather than data collected retrospectively during bereavement.

\section{The Absence of Grief: Pathology or Resilience?}

Historically, bereavement theorists have emphasized the importance of working through the emotional pain of the loss, and have viewed the absence of overt grieving as indicative of psychopathology (Bowlby, 1980; Deutsch, 1937; Jacobs, 1993; Lindemann, 1944; Osterweis, Solomon, \& Green, 1984; Rando, 1993; Worden, 1991). In a survey of bereavement researchers and expert clinicians (Middleton et al., 1993), a majority (65\%) endorsed beliefs that "absent grief" usually stems from denial or inhibition, and that it is generally maladaptive in the long run. Increasingly, however, investigators have challenged this assumption, arguing that some people do not show overt signs of distress because of quick adjustment following expected loss (M. S. Stroebe, Hansson, \& Stroebe, 1993), or because of personality factors that promote an inherent resilience to loss (Bonanno et al., in press; Neimeyer \& Levitt, 2001).

There is compelling evidence that sizable numbers of conjugally bereaved individuals do not exhibit significant distress or depression following the loss (e.g., 78\% in Lund et al., 1985-1986; 58\% in Bournstein et al., 1973; for reviews of this literature, see Bonanno \& Kaltman, 1999, 2001; and Wortman \& Silver, 2001). In fact, recent studies have documented that most conjugally bereaved failed to show even mild dysphoria (Bruce, Kim, Leaf, \& Jacobs, 1990; Cleiren, 1993; Zisook, Paulus, Shuchter, \& Judd, 1997). The prevalence of this pattern alone calls into question the assumption that such a reaction is pathological, and suggests that a greater understanding of resilience during bereavement should become an important research priority.

\section{Delayed Grief and Improved Functioning During Bereavement}

From a traditional perspective, the absence of overt signs of grieving only means that depression will eventually be manifested as a delayed reaction (e.g., Bowlby, 1980; Deutsch, 1937; Osterweis et al., 1984; Parkes \& Weiss, 1983; Rando, 1993, Sanders, 1993). In the study by Middleton et al. (1993), $76 \%$ of clinicians and bereavement researchers surveyed believed that delayed grief was a genuine phenomenon. However, in each of the six aforementioned studies, the percentage of respondents showing this pattern (i.e., low initial distress to high distress at a subsequent time point) was extremely low, ranging from $2.5 \%$ (Vachon, Rogers, et al., 1982) to $0 \%$ (Bonanno et al., 1995; Zisook \& Schuchter, 1986). Bonanno and Field (2001) did not find clear evidence for delayed grief among conjugally bereaved individuals who were assessed over a 5-year period using multiple outcome measures. Similarly, following cluster analyses of several different types of bereaved samples, Middleton et al. (1996) concluded that 
"no evidence was found for the pattern of response which might be expected for delayed grief” (p. 169).

What about the possibility that some individuals might actually show improved psychological health after the death of their spouse? This idea runs against the grain of traditional views of bereavement. However, several theorists have noted that when a spouse has a serious illness, or when the marital relationship is characterized by high degrees of stress, the death may provide relief or fortuitous escape from a chronically stressful situation (Bodnar \& Kiecolt-Glaser, 1994; Cohen \& Eisdorfer, 1988; A. Horowitz, 1985; Wheaton, 1990). Because the vast majority of bereavement studies have not assessed depression until after the loss, little is known about conditions under which depression may improve following a loss.

In summary, those few studies that report percentages of respondents exhibiting different patterns of response following the loss of a spouse indicate that a sizable minority evidence chronic grief reactions. Because all of these studies assessed distress only following the loss, it is possible that this group is actually comprised of two subgroups: one that manifests an intense reaction to the loss, and one that exhibits elevated distress symptoms both before and after the loss. A surprising finding emerging from these studies is that, although many participants exhibit common, timelimited grief reactions, a substantial percentage of respondentsand sometimes a majority of respondents-exhibit little or no distress following the loss. These participants too may actually be comprised of two subgroups: a resilient group who exhibit little distress both prior to and after their spouse's death, and another subgroup who were distressed prior to the loss, but improved following their spouse's death.

To account for these concerns in the current study, we examined patterns of change in depression in a sample of conjugally bereaved adults at preloss and at 6 and 18 months after the death of their spouses. We first categorized participants into low and high preloss depression, and then considered changes in depression separately for each group using the group's standard deviation. This approach helped control for regression to the mean among the high-depression participants. We expected to observe the three basic bereavement outcome patterns detected in previous studies that included only postbereavement data (i.e., common grief, chronic grief, and absent grief). On the basis of the studies reviewed earlier, we did not expect to find evidence for a delayed grief reaction. Of importance, the inclusion of preloss depression scores in the present study made it possible (a) to empirically distinguish chronic grief from chronic depression and (b) to distinguish a stable low depression or resilient pattern from improved functioning. Because grief reactions include symptoms other than depression (Shuchter \& Zisook, 1993), we also examined the extent to which each of these patterns was associated with other symptoms of grief (e.g., yearning). ${ }^{1}$

\section{Preloss Predictors of Divergent Reactions to Conjugal Loss}

The literature contains numerous hypotheses about the possible antecedents of these different patterns of grief reaction. These hypotheses have been generated almost exclusively on the basis of data gathered from bereaved individuals after the death of their spouse. Consequently, it is not clear whether these observations actually pertain to chronic grief and resilience or to chronic de- pression or depression followed by improved functioning during bereavement. To address this concern in the current study, we first delineated a set of preloss variables that have been associated in previous work with the chronic and absent grief patterns. We included variables from each of four fundamental components of bereavement identified by Bonanno and Kaltman (1999) in their integrative review of the literature: qualities of the relationship, coping, meaning, and context. Next, we examined how well these preloss variables predicted the various patterns of grief reaction.

\section{Qualities of the Conjugal Relationship}

One of the most widely held assumptions in the literature is that chronic grief results from conflict in the conjugal relationship (Parkes \& Weiss, 1983; W. Stroebe \& Stroebe, 1993). A related assumption is that chronic grief arises out of ambivalence toward the spouse (e.g., Bowlby, 1980; M. J. Horowitz, Bonanno, \& Holen, 1993; Lindemann, 1944; Parkes \& Weiss, 1983). Still a third variant on this hypothesis links chronic grief to excessive dependency (Lopata, 1979, Osterweis et al., 1984, Parkes \& Weiss, 1983; Raphael, 1983), either as a feature of the conjugal relationship (e.g., "pathological dependence" on the partner; Raphael, 1983, p. 208) or as a more broadly based personality characteristic (Prigerson, Shear, Frank, \& Beery, 1997; Sable, 1989).

A personality characteristic related to dependency that has interested bereavement researchers is attachment style (M. S. Stroebe \& Schut, 2001). Shaver and colleagues suggested, for instance, that individuals with an "anxious/ambivalent" or "preoccupied" attachment style tend to react to the loss of a loved one with intense and prolonged distress (see, e.g., Fraley \& Shaver, 1999; Shaver \& Tancredy, 2001). Of interest, these authors also maintained that anxious/ambivalent individuals are likely to be distressed and preoccupied with the relationship prior to the loss (Shaver \& Tancredy, 2001). This latter consideration suggests the intriguing possibility that chronically depressed or depressedimproved individuals, more so than chronically grieved individuals, may exhibit relationship ambivalence.

Attachment style has also been evoked as an explanation for absent grief. Several investigators have suggested that bereaved individuals who fail to show overt grief reactions were only superficially attached to their conjugal partner (Fraley \& Shaver, 1999; M. J. Horowitz, 1990; Rando, 1988, 1993), therefore obviating the need for grief (Raphael, 1983). One obvious reason why this situation may have arisen is prolonged relationship conflict (i.e., a bad marriage). It has also been suggested that people who show little grief tend to be emotionally distant people (Bowlby, 1980; Rando, 1993). In a related vein, Shaver and Tancredy (2001) suggested that individuals with an avoidant or dismissing attach-

\footnotetext{
${ }^{1}$ There are a number of possible methods that might be used to identify distinct patterns of grief reaction. We chose to use change scores as described above because this approach is relatively more straightforward and follows relatively easy to understand rules of categorization compared with other methods. The most likely alternative method was cluster analyses, which have been used in a past study of bereaved respondents (Middleton et al., 1996). However, cluster analyses suffer from several disadvantages, the most prominent being (a) that there is no one agreed upon clustering method, with different disciplines favoring different methods, and (b) that each method tends to produce slightly different results (Aldenderfer \& Blashfield, 1984).
} 
ment style limit the extent to which they depend emotionally on their relationship partner, therefore displaying relatively little distress when the relationship ends. Consistent with this reasoning, avoidant individuals reported less distress than other individuals following the break of a romantic relationship (Simpson, 1990).

\section{Coping Resources}

Coping resources are often noted as playing a crucial role in moderating adjustment to stressful life events, including interpersonal loss (Bonanno \& Kaltman, 1999; W. Stroebe \& Stroebe, 1987). Included among such resources are personality traits associated with coping efficacy (M. J. Horowitz et al., 1993; NolenHoeksema \& Larson, 1999; W. Stroebe \& Stroebe, 1987). For example, emotional stability (low Neuroticism) is viewed as an interpersonal resource that buffers an individual from the destabilizing nature of conjugal loss (W. Stroebe \& Stroebe, 1987, 1993; Vachon, Sheldon, et al., 1982). Other traits that might serve as a buffer against loss are Conscientiousness, Agreeableness, Openness to Experience, the tendency to introspect, and perceived confidence in coping (e.g., Lund et al., 1985-1986).

Religious involvement may also be conceptualized as a coping resource. Religion can foster resilience during bereavement both by providing a stable, shared belief system and by providing affiliation and social support from the religious community (McIntosh, Silver, \& Wortman, 1993; Nolen-Hoeksema \& Larson, 1999; Shuchter \& Zisook, 1993; W. Stroebe \& Stroebe, 1993). Recent factor analytic studies of religious involvement have identified two unique dimensions, personal devotion (a personal relationship with the divine) and personal conservatism (a personal commitment to teaching and living according to a creed), that appear to exert a salubrious influence among at-risk individuals (Kendler, Gardner, \& Prescot, 1997; Miller, Davies, \& Greenwald, 2000).

\section{Meaning (World View)}

Numerous bereavement investigators have maintained that finding meaning is a core component of the grieving process (Davis \& Nolen-Hoeksema, 2001; Neimeyer, 2000; Parkes, 1971; Schwartzberg \& Janoff-Bulman, 1991). However, a significant percentage of bereaved people report that they search for but are unable to find any meaning in a loss (Davis \& Nolen-Hoeksema, 2001; Lehman, Wortman, \& Williams, 1987), and these individuals tend to have more prolonged grief reactions than other participants (Davis, Wortman, Lehman, \& Silver, 2000). A related line of research has associated chronic grief with views of the world as meaningless, unjust and uncontrollable (Schwartzberg \& Janoff-Bulman, 1991). Together, these data are consistent with social-cognitive models that suggest that the death of a spouse can shatter a person's belief system and prolong the grieving process (Janoff-Bulman, 1992; Parkes, 1971, 1998).

Conversely, another sizable group of individuals report that they do not actively search for meaning following loss, and these individuals appear to adjust well to trauma or loss (Davis et al., 2000; Downey, Silver, \& Wortman, 1990; Lehman et al., 1987). One of the most compelling explanations for this association is that these individuals hold a priori beliefs about themselves and the world that can more readily accommodate the possibility of loss, thereby minimizing the need to search for explanation for the loss. For example, individuals whose world view includes an accep- tance of death may be more able to assimilate their partner's death than individuals who are uncomfortable with or fear death. Similarly, individuals who believe that generally speaking, the world is a just and fair place may find it easier to accept their spouse's death and this may afford them some comfort in dealing with the loss. It is also possible that those who hold relatively negative views of the world (e.g., as unjust or uncontrollable) will react with greater distress following a loss event. For such individuals, the loss event may confirm their negative world view and thereby contribute to their spiraling distress (see Davis et al., 2000).

\section{Context}

We noted earlier that losses occurring in the context of serious spousal illness, especially when intensive caregiving is required, could be experienced as a relief from a chronic stress and, as a result, lead to improved psychological health during bereavement. Another contextual factor is supportive resources. Two types of support that have been examined in the bereavement literature are perceived social support from friends and relatives (Bonanno \& Kaltman, 1999; Lopata, 1979; Nolen-Hoeksema \& Larson, 1999; Sanders, 1993; W. Stroebe \& Stroebe, 1987) and instrumental support, such as financial resources or help in the maintenance of home and familial responsibilities (W. Stroebe \& Stroebe, 1987).

Many of the hypothesized predictors of grief course reviewed above have received partial empirical support, many have generated mixed results, and some have not yet been examined empirically (for a review, see Bonanno \& Kaltman, 1999). Of greater importance, these hypothesized predictor variables have not been examined using preloss measures. To address this deficit in the current study, we formalized two sets of predictions regarding the relationship of specific preloss factors and the bereavement patterns. The first set of predictions represented the contrasting profiles of chronic grievers as relatively maladjusted individuals with few coping resources and resilient individuals as relatively healthy individuals with more abundant coping resources. This view was formalized in predictions that, compared with resilient individuals, chronic grievers at preloss would have (a) a poorer quality relationship with their spouse (less positive, more negative evaluations of the marriage; greater ambivalence about their spouse; greater dependency); (b) fewer coping resources (lower self-perceived coping efficacy; lower religiosity); (c) a more vulnerable world view (less acceptance of death; belief that the world is unjust and uncontrollable), and (d) a less favorable preloss context (less perceived social support; fewer instrumental supports). This view also predicts that common grievers would score at an intermediate level on each variable, between the chronic grief and resilient groups.

A second, competing set of predictions represented the traditional view that bereaved individuals who do not show overt signs of grieving are not resilient but rather lack interpersonal warmth and skill, are unable to form mature attachments, and have poor quality marriages. This view was formalized in predictions that prior to the loss, the group we labeled as resilient would in fact report greater conflict (less positive, more negative evaluations of the marriage), show an avoidant/dismissive attachment style, and would be rated by interviewers as having less interpersonal comfort, skill, and warmth compared with common and chronic grievers. 
In addition to these two sets of predictions, we examined whether factors hypothesized in the bereavement literature to be precursors of either chronic grief or resilience may be more reliably associated with chronic depression or depression followed by improvement during bereavement. As we noted earlier, in the absence of data on preloss functioning, chronic grief may be confused with chronic depression, and resilience may be confused with improved functioning following a loss. As a result, observations about the precursors to chronic grief or resilience may be unavoidably confounded with observations of chronically depressed and depressed-improved individuals, respectively. Finally, we considered exploratory hypotheses that the depressed-improved group would be more likely to have an ill spouse, and more likely to be involved in a burdensome caregiving relationship than other participants.

\section{Method}

\section{Participants}

Bereaved participants' data were obtained as part of the Changing Lives of Older Couples (CLOC) study, a prospective study of a two-stage area probability sample of 1,532 married individuals from the Detroit Standardized Metropolitan Statistical Area (SMSA). To be eligible for the CLOC study, respondents had to be English-speaking, married, and the husband was age 65 or older. All sample members were noninstitutionalized and capable of participating in a $2-\mathrm{hr}$ interview. Approximately $65 \%$ of those contacted for an interview participated, which is consistent with the response rate from other Detroit area studies. Baseline interviews were conducted from June 1987 through April 1988.

Participants from the CLOC study who subsequently lost a spouse were identified using daily obituaries in three Detroit-area newspapers and monthly death record tapes provided by the State of Michigan. The National Death Index (NDI) was used to confirm deaths and obtain causes of death. Widowed participants were invited for follow-up interviews at 6 and 18 months after the spouses' death. Of the 319 respondents who lost a spouse during the CLOC study, $86 \%(n=276)$ participated in at least one follow-up interview and $64 \%(n=205)$ participated in both follow-up interviews. The primary reasons for nonresponse were ill health or death at follow-up (42\%) and refusal to participate (38\%). Analyses in the present study were based on the 205 widowed persons (180 women and 25 men) who had participated in both follow-up interviews. Participants who remained in the study or dropped out did not differ significantly in preloss depression $(p>15)$. Participants' average age at 6-months postloss was $72(S D=6.5)$ years. For more information on the sample, see Carr, House, Nesse, Sonnega, \& Wortman, in press.

\section{Measures of Adjustment}

Depressive symptoms were measured using the Center for Epidemiologic Studies Depression (CES-D) Scale (Radloff, 1977). The CES-D has shown adequate test-retest reliability and internal consistency across a wide range of subsamples (Roberts, Rhoades, \& Vernon, 1990) and discriminates meaningfully between depressed patients and controls (Boyd, Weissman, Thompson, Myers, \& Jerome, 1982). The present study used a brief, nine-item version of the CES-D that has shown comparable reliability and validity statistics (Kohut, Berkman, Evans, \& Cornoni-Huntley, 1993). Respondents were asked to indicate how often they felt or experienced each symptom in the week prior to the interview (I felt depressed; I felt that everything I did was an effort; My sleep was restless; I was happy; I felt lonely; I enjoyed life; I did not feel like eating, my appetite was poor; I felt sad; I could not get going). Internal consistency for the nine-item version was .85 .
Grief symptoms were measured using 16 items derived from the Bereavement Index (Jacobs, Kasl, \& Ostfeld, 1986), the Present Feelings About Loss Scale (Singh \& Raphael, 1981) and the Texas Revised Inventory of Grief (Zisook, DeVaul, \& Click, 1982). The items represented five domains of grief symptoms: yearning (having painful waves of missing your spouse?), despair (felt life had lost its meaning?), anxiety (afraid of what is ahead?), shock (couldn't believe what was happening?), and intrusive thoughts (couldn't get thoughts about him/her out of your mind?) Internal consistency for the total grief-specific symptom score was .88 . Although grief symptoms were highly correlated with CES-D scores at 6 months $(r=.63, p<.001)$ and 18 months $(r=.60, p<.001)$, their relationship was far from perfect, thus suggesting some uniqueness to the constructs (for a more detailed analyses of the structure of the grief items and their distinction from depression in this same sample, see Vinokur et al., 2002).

\section{Bereavement Patterns From Preloss to 18-Months Postloss}

Step 1: Categorization of high/low preloss depression scores. Each participant's CES-D score was converted to a standardized $z$-score based on the distribution of the entire CLOC sample $(N=1,532)$ at each wave of data collection. The cutoff point for clinically relevant levels of depression on the CES-D has commonly been set at the 80th percentile (e.g., Comstock \& Helsing, 1976) or higher (e.g., Myers \& Weissman, 1980). Because lower cutoffs are generally more appropriate for older samples (e.g., Lund et al., 1985-1986), we adopted the 80th percentile $(z$-score $=$ $.87)$ as a cutoff for high depression. Forty-nine participants were categorized as having high baseline depression $(M=1.61, S D=0.88)$ and 156 participants as having low baseline depression $(M=-0.39, S D=0.57){ }^{2}$

Step 2: Defining change from preloss to 6- and 18-months postloss. Two change scores were calculated for each participant by comparing CES-D scores at preloss with the 6-month follow-up, and with the 18month follow-up. Change scores were then categorized as follows. A grief reaction was assigned when depression increased relative to preloss by one standard deviation or greater. No change was assigned when depression scores remained constant or increased or decreased by less than one standard deviation. Improved functioning was assigned when depression decreased by greater than one standard deviation. In addition, to accommodate the possibility that participants with extremely high or extremely low preloss depression scores might show decreased or increased depression during bereavement in part because of regression to the mean, we added two further rules. First, we defined change separately for the high and low preloss depression groups using the standard deviation of each group. Meaningful change was defined as .88 standard units for participants with high preloss depression and .57 standard units for participants with low preloss depression. Second, because preloss depression scores tended to cluster around the sample mean, a grief reaction was assigned only when depression scores during bereavement increased to greater than the $50 \%$ percentile for the larger sample $(N=1,532, z=0)$.

Step 3: Defining patterns of change from preloss to 18-months postloss. The categories created in Steps 1 and 2 were used to create four possible outcome patterns for low preloss depression individuals and four possible outcome patterns for high preloss depression individuals. Participants with low preloss depression were assigned to one of the following four patterns. The common grief pattern was assigned to low preloss depression partic-

\footnotetext{
${ }^{2}$ Cutoff points for high and low baseline depression are always to some extent arbitrary. We explored several additional cutoff points at higher and lower levels of depression. Although in each case, different cutoff points resulted in a slightly different distribution of participants into the grief outcome patterns, the different cutoff points did not influence the relationship of the grief patterns to prebereavement predictors. In other words, the same basic pattern of findings was evidenced regardless of slight variations in the cutoff for high/low depression.
} 
ipants who had a grief reaction at 6 months, but did not differ from their preloss levels at the 18-month point of bereavement. The resilient pattern was assigned to low preloss depression participants who showed no change at both 6 or 18 months of bereavement. The delayed grief pattern was assigned to low preloss depression participants who showed no change at 6 months, but had a grief reaction at 18 months. Finally, the chronic grief pattern was assigned to low preloss depression participants who showed grief reactions at both 6 and 18 months of bereavement.

Participants with high preloss depression were assigned to one of the following four patterns. The chronic depression pattern was assigned to high preloss depression participants who showed no change at both 6 and 18 months of bereavement. The depressed-improved pattern was assigned to high preloss depression participants who showed improved functioning at both 6 and 18 months of bereavement. We also defined two patterns that have not been discussed in the literature but are logically possible. The delayed-improved pattern was assigned to high preloss depression participants who showed no change at 6 months, but showed improved functioning at 18 months of bereavement. Finally, the improvedrelapsed pattern was assigned to high preloss participants who showed improved functioning at 6 months, but were no longer different from their preloss level of depression at 18 months of bereavement.

\section{Preloss Predictor Variables}

Qualities of the marriage. Participants' perceptions of the quality of their marriage were assessed by using 10 items adapted from the Dyadic Adjustment Scale (Spanier, 1976). Positive evaluations of the marriage were measured by averaging four items: "How much does your (husband/ wife) make you feel loved and cared for?"; "How much is (he/she) willing to listen when you need to talk about your worries or problems?"; "Thinking about your marriage as a whole, how often do you feel happy about it?"; "Taking all things together, how satisfied are you with your marriage?" $(\alpha=.85)$. Negative evaluations of the marriage were measured by averaging six items: "How much do you feel (he/she) makes too many demands on you?"; "How much is (he/she) critical of you or what you do?"; "There are some serious difficulties in our marriage"; "My (husband/ wife) doesn't treat me as well as I deserve to be treated"; "How often would you say you and your (husband/wife) typically have unpleasant disagreements or conflicts?"; "How often do you feel bothered or upset by your marriage?" $(\alpha=.79)$.

Ambivalence about the spouse/marriage was calculated following a procedure used to measure ambivalent attitudes (Kaplan, 1972; Scott, 1966; Thompson \& Zanna, 1995). In this method, the separate positive and negative evaluations of the conjugal relationship (described above) were standardized and then combined algorithmically into a single index of ambivalence, such that extreme ratings in both the positive and the negative direction produce higher ambivalence scores. Preliminary support for the validity of this approach as a measure of ambivalence toward a spouse was demonstrated in a previous study (Bonanno, Notarius, Gunzerath, Keltner, \& Horowitz, 1998). To provide additional validity for the ambivalence algorithm, participants in the current study were asked the following question: "In some marriages there are times when you feel very close, but other times when you can get more upset with that person than with anyone else. How much does this sound like the relationship you have with your husband/wife?" This question correlated positively with the ambivalence algorithm $(r=.45, p<.001)$.

The general trait of interpersonal dependency was measured by averaging five items from Hirschfeld's (1977) Interpersonal Dependency Scale: "The idea of losing a close friend is terrifying to me"; "I think that most people don't realize how easily they can hurt me"; "I tend to imagine the worst if a loved one doesn't arrive when expected"; "I would feel hopeless if I were deserted by someone I love"; "I have always had a terrible fear that I will lose the love and support of people I desperately need" ( $\alpha=$ .75). A more specific measure of dependency on the spouse was developed for this study by averaging four items: "The idea of losing my (husband/ wife) is terrifying to me"; "No one could ever take the place of my (husband/wife)"; "If my (husband/wife) died, it would be the worst thing that could happen to me"; "I would feel completely lost if I didn't have my (husband/wife)" ( $\alpha=.80)$.

Avoidant/dismissive attachment was measured by averaging four items from Hirschfeld's (1977) Autonomy Scale: "I don't need much from people"; "What people think of me doesn't affect how I feel"; "What other people say doesn't bother me"; "I don't need other people to make me feel good" $(\alpha=.75)$.

After the preloss interview, the interviewer rated participants' level of interpersonal comfort (On the basis of your experience with the respondent in the interview, how comfortable would you say respondent is with other people?), skill (How skilled would you say respondent is in handling or dealing with other people?), and warmth (How warm or cold was respondent to you?).

Coping resources. Participants' confidence in their own coping ability was measured by averaging four items: "I often feel helpless and want someone else to solve my problems"; "I can handle myself pretty well in a crisis"; "When I'm under a great deal of stress sometimes I feel like I'm going to pieces"; "When everything seems to be going wrong, I can still make good decisions" $(\alpha=.60)$.

Religiosity was measured using two dimensions identified in factor analytic studies of large, national samples (Kendler et al., 1997; Miller et al., 2000). Personal devotion was measured by averaging four items: "In general, how important are religious or spiritual beliefs in your day-to-day life?"; "How often do you usually attend religious services?"; "When you have problems or difficulties in your family, work, or personal life, how often do your seek spiritual comfort and support?"; "When you have decisions to make in your everyday life, how often do you ask yourself what God would want you to do?" $(\alpha=.83)$. Religious conservatism was measured by averaging three items: "Would you say that you have been 'born again,' that is, had a turning point in your life when you committed yourself to Jesus Christ?"; "Do you ever try to encourage people to believe in Jesus and to accept Him as their Savior?"; "Please tell me whether you agree or disagree with the following statement: The Bible is the actual Word of God and is to be taken literally, word for word" ( $\alpha=.65)$.

Dimensions of the five-factor model of personality (Neuroticism, Agreeableness, Openness, Extraversion, and Conscientiousness) were measured using an abbreviated version of the NEO Personality Inventory (NEO-PI; Costa \& McCrae, 1992). ${ }^{3}$ The tendency toward introspection was measured using three items: "I often think about why my life is the way it is"; "I often think about how I feel"; "I often wonder about the real reason I behave as I do" $(\alpha=.75)$.

World view. Belief in a just world was measured by averaging six items: "In the long run, good people will be rewarded for the good things they have done"; "By and large, people deserve what they get"; "People who meet with misfortune have often brought it on themselves"; "Eventually, everybody gets what is coming to them"; "In the long run, people get the respect they deserve"; "It is only a matter of time before the bad people will be punished for the bad things they have done" $(\alpha=.76)$. Belief in personal injustice (i.e., that the world is particularly unjust to oneself) was measured by averaging three items: "When I look back on what has happened to me, I feel cheated"; "I don't seem to get what should be coming to me"; "Other people always seem to get the breaks" $(\alpha=.77)$. Belief in the uncontrollability of negative events was measured by averaging four items: "I am certain something bad could happen to me at any time"; "I am certain something bad could happen to one of my loved ones at any time"; "Bad things can happen to anyone at any time"; "People who think catastrophes cannot happen to them are kidding themselves" ( $\alpha=$ .67). Acceptance of death was measured by averaging four items: "Death is simply part of the process of life"; "I don't see any point in worrying

\footnotetext{
${ }^{3}$ The shortened form of the NEO-PI was developed specifically for inclusion in this study by Paul Costa, one of the original authors of the scale.
} 
about death"; "I would neither fear death nor welcome it"; "I am resigned to the fact that we all have to die" $(\alpha=.57)$.

Context. Data on spouses' health and whether or not the participant engaged in caregiving were obtained from interviews conducted at 6-months postloss. Spousal illness was measured by asking if the spouse had "serious ongoing health problems" prior to his/her death. Caregiving was measured in terms of hours per week, and coded as a binary variable of providing care or not providing care. Caregiving strain was measured using two questions that asked about the degree that caregiving was experienced as stressful and the extent that caregiving interfered with other activities. Because responses to these questions were highly correlated $(r=$ $.85, p<.001)$, participants were categorized as having high caregiving strain when they endorsed moderate to extreme levels on both items.

Participants' ratings of perceived support from friends and relatives was measured by averaging two questions: "On the whole, how much do your friends and relatives make you feel loved and cared for?"; "How much are your friends and relatives willing to listen when you need to talk about your worries or problems?" $(\alpha=.71)$. Perceived support from children was measured by averaging two questions: "How much do your children make you feel loved and cared for?"; "How much are they willing to listen when you need to talk about your worries or problems?" $(\alpha=.70)$. The availability of instrumental support from family and friends (other than spouse or child) was measured by averaging three questions: "If you and your (husband/wife) needed extra help with general housework or home maintenance, how much could you count on friends or family members to help you?"; "If you and your (husband/wife) needed extra money, how much could you count on someone, other than a lending institution, to lend or give you money?"; "If you were ill, how much could you count on someone, besides your (husband/wife), to make sure you are taken care of?" $(\alpha=.68)$.

\section{Results}

\section{Bereavement Patterns}

On the basis of the conceptual distinctions discussed earlier, we anticipated that most bereaved participants could be categorized into these five patterns: common grief; chronic grief; resilience; chronic depression; depression-improvement. Owing to the relative rarity of delayed grief in previous studies, we expected that few participants would show this pattern in the current study. Likewise, owing to the lack of empirical evidence for either the delayed-improved or the improved-relapsed patterns, we also expected relatively few participants to exhibit these patterns.
As anticipated, most of the sample $(n=185 ; 90.2 \%)$ were captured by five conceptually relevant patterns: common grief $(n=22 ; 10.7 \%)$; chronic grief $(n=32 ; 15.6 \%)$; resilient $(n=$ 94; 45.9\%); chronic depression $(n=16 ; 7.8 \%)$; and depressedimproved $(n=21 ; 10.2 \%)$. Also as expected, the remaining 20 participants $(9.8 \%)$ were spread sparsely across the delayed grief ( $n=8 ; 3.9 \%)$, delayed-improved $(n=10 ; 4.9 \%)$, and improvedrelapsed $(n=2 ; 1.0 \%)$ patterns. Because each of these patterns accounted for less than $5 \%$ of the sample, they were not used for the primary data analyses. However, after completing the primary data analyses, we explored whether absorbing the underrepresented patterns into other patterns influenced the results (see Footnote 4).

Group differences in depression at preloss, and at 6- and 18-months postloss. Depression scores at each assessment are listed in Table 1 and depicted graphically in Figure 1 for the five most common bereavement patterns. A series of analyses of variance (ANOVAs) and pairwise comparisons were conducted to examine group differences in depression scores at each wave of assessment (see Table 1). Prior to bereavement, the common grief, chronic grief, and resilient patterns did not differ from each other, and had significantly lower levels of depression than chronically depressed individuals, who were in turn significantly lower than depressed-improved participants. At 6-months postloss, all five groups had significantly different levels of depression with the resilient group lowest, followed in ascending order by depressedimproved participants, common grievers, chronic grievers, and chronically depressed participants. At 18-months postloss, the resilient and common grievers had the lowest depression and did not differ significantly from each other. Depressed-improved respondents were significantly more depressed than the resilient group. Chronic grievers and chronically depressed individuals did not differ significantly from each other, and both were significantly more depressed than the other groups.

Group differences in grief symptoms at 6- and 18-months postloss. Grief total scores at each assessment are listed in Table 1 and depicted graphically in Figure 2 for the five bereavement patterns. Each group reported at least some grief symptoms and showed a decline in grief symptoms over time. At 6-months postloss, resilient individuals had fewer grief symptoms than all other groups except the depressed-improved group. Chronic griev-

Table 1

Means (and Standard Deviations) of Depression and Grief Symptoms for Each Bereavement Pattern at Each Wave of Data Collection

\begin{tabular}{|c|c|c|c|c|c|c|}
\hline \multirow[b]{2}{*}{ Outcome measure } & \multicolumn{5}{|c|}{ Bereavement pattern } & \multirow[b]{2}{*}{$F(4,180)$} \\
\hline & $\begin{array}{l}\text { Resilient } \\
(N=95)\end{array}$ & $\begin{array}{l}\text { Depressed- } \\
\text { improved } \\
(N=21)\end{array}$ & $\begin{array}{l}\text { Common grief } \\
\quad(N=22)\end{array}$ & $\begin{array}{l}\text { Chronic grief } \\
\quad(N=31)\end{array}$ & $\begin{array}{l}\text { Chronic } \\
\text { depression } \\
(N=16)\end{array}$ & \\
\hline \multicolumn{7}{|l|}{ Depression } \\
\hline Preloss & $-0.34(0.60)_{\mathrm{a}}$ & $2.02(1.14)_{\mathrm{b}}$ & $-0.45(0.57)_{\mathrm{a}}$ & $-0.53(0.47)_{\mathrm{a}}$ & $1.16(0.28)_{\mathrm{c}}$ & $79.93 * * *$ \\
\hline 6-months postloss & $-0.44(0.53)_{\mathrm{a}}$ & $-0.07(0.85)_{\mathrm{b}}$ & $0.76(0.71)_{\mathrm{c}}^{\mathrm{a}}$ & $1.30(0.84)_{\mathrm{d}}$ & $1.77(0.67)_{\mathrm{e}}$ & $70.06^{* * *}$ \\
\hline 18 -months postloss & $-0.54(0.53)_{\mathrm{a}}$ & $-0.17(0.92)_{\mathrm{b}}$ & $-0.41(0.51)_{\mathrm{ab}}$ & $1.38(1.03)_{\mathrm{c}}$ & $1.65(0.79)_{\mathrm{c}}$ & $67.45 * * *$ \\
\hline \multicolumn{7}{|l|}{ Grief symptoms } \\
\hline 6-months postloss & $4.17(2.32)_{\mathrm{a}}$ & $5.02(2.86)_{\mathrm{ab}}$ & $6.30(2.77)_{\mathrm{b}}$ & $8.29(2.63)_{\mathrm{c}}$ & $8.67(3.15)_{\mathrm{c}}$ & $22.17 * * *$ \\
\hline 18 -months postloss & $2.76(3.64)_{a}$ & $2.73(4.96)_{a}$ & $2.68(5.04)_{a}$ & $5.94(7.50)_{\mathrm{b}}$ & $5.04(9.38)_{\mathrm{b}}$ & $19.28 * * *$ \\
\hline
\end{tabular}

Note. Cell means that share subscripts across each row do not differ significantly $(p>.05)$.

$* * * p<.001$. 


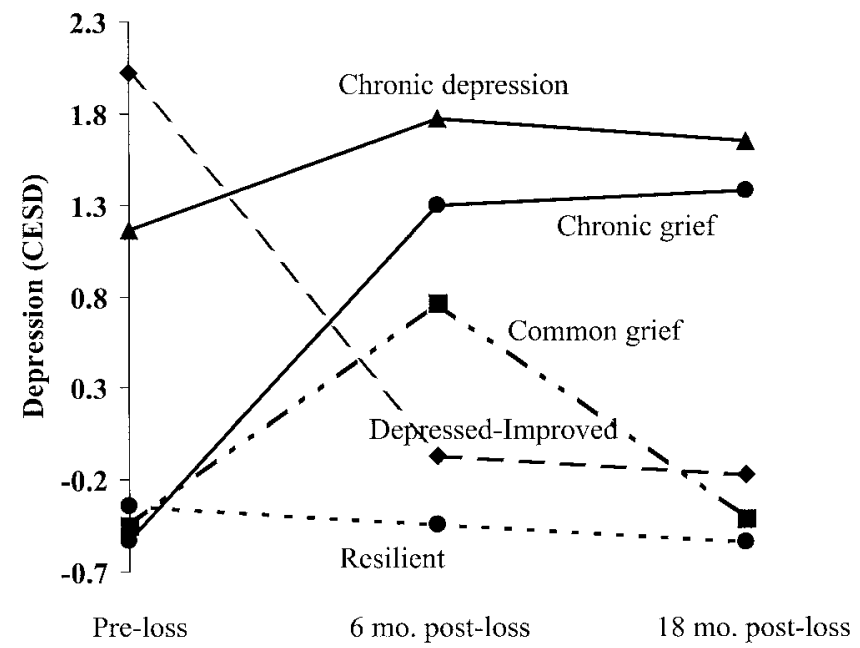

Figure 1. Patterns of depression (Center for Epidemiologic Studies Depression [CES-D] scores) from preloss to 18 -months postloss $(N=185)$.

ers and chronically depressed individuals did not differ from each other, and had greater grief than all other groups. At 18-months postloss, the resilient, common, and depressed-improved groups did not differ significantly, and each had less grief than chronic grievers and chronically depressed individuals, who again did not differ from each other.

Time from preloss to 6-months postloss. The average duration from the time of the preloss assessments to the first assessment during bereavement was 36.7 months ( $S D=16.6$ months). A one-way ANOVA examining this time interval across the five bereavement patterns did not approach significance, $F(4,180)=$ $0.63, p=.51$. This variable was not considered further.

\section{Preloss Predictors of the Bereavement Patterns}

Each preloss predictor variable was first considered as the dependent variable in a one-way ANOVA for differences across the five types of grief reaction. Significant omnibus group differences were followed up by pairwise comparisons for (a) predicted differences between resilient, common grief, and chronic grief, and (b) differences between chronically depressed and depressedimproved individuals and other participants. These results are summarized in Table 2.

Qualities of the conjugal relationship. The hypothesis that chronic grief results from conflict with and ambivalence toward the spouse and that resilient individuals had relatively welladjusted marriages was formalized into predictions that prior to the loss, chronic grievers would evaluate their spouse/marriage less positively and more negatively, and that they would be more ambivalent about the spouse/marriage than resilient individuals. The competing hypothesis that the absence of grief results from the end of a bad marriage was formalized into predictions that the resilient group would have less positive and more negative evaluations of the conjugal relationship, and would be more ambivalent about the relationship. Pairwise comparisons failed to confirm any of these hypotheses; No significant differences were found between the resilient, common grief, and chronic grief groups.

Depressed-improved individuals had the least positive and most negative evaluations of their spouse/marriage, and were the most ambivalent about their spouse/marriage of any group of participants. Pairwise comparisons revealed that depressed-improved individuals were significantly less positive, more negative, and more ambivalent about their spouse/marriage than resilient, chronic grief, and common grief individuals. Chronically depressed individuals did not differ from other participants on these variables, with the sole exception that they were less positive about their spouse/marriage than chronic grievers. Together, these findings indicate that the relatively poor quality of marriage hypothesized to underlie the absence of grief and the intense ambivalence associated with chronic grief were instead associated with individuals with high preloss depression who improved during bereavement.

The hypothesis that chronic grief results from extreme dependency was formalized into predictions that chronic grievers would report greater general interpersonal dependency, and greater dependency in their relationship with the spouse than resilient individuals. Significant group differences were observed for both dependency variables. Consistent with this prediction, chronic grievers were significantly higher on both dependency on the spouse and interpersonal dependency than the resilient group. Common grievers scored at an intermediate level for each variable and were not significantly different from either the chronic grief or resilient group.

Chronically depressed individuals actually showed the highest levels of both interpersonal dependency and dependence on the spouse. Further, chronic grievers and chronically depressed individuals did not differ significantly on either dependency variable, and both groups were significantly higher in interpersonal dependency than the resilient group. Chronically depressed individuals were also higher in interpersonal dependency than common grievers and depressed-improved individuals, but did not differ significantly from any group in dependence on the spouse. In a similar vein, depressed-improved individuals showed relatively low levels of both interpersonal dependency and dependence on the spouse, and did not differ significantly from the resilient group on either variable. Together, these results indicate that despite different

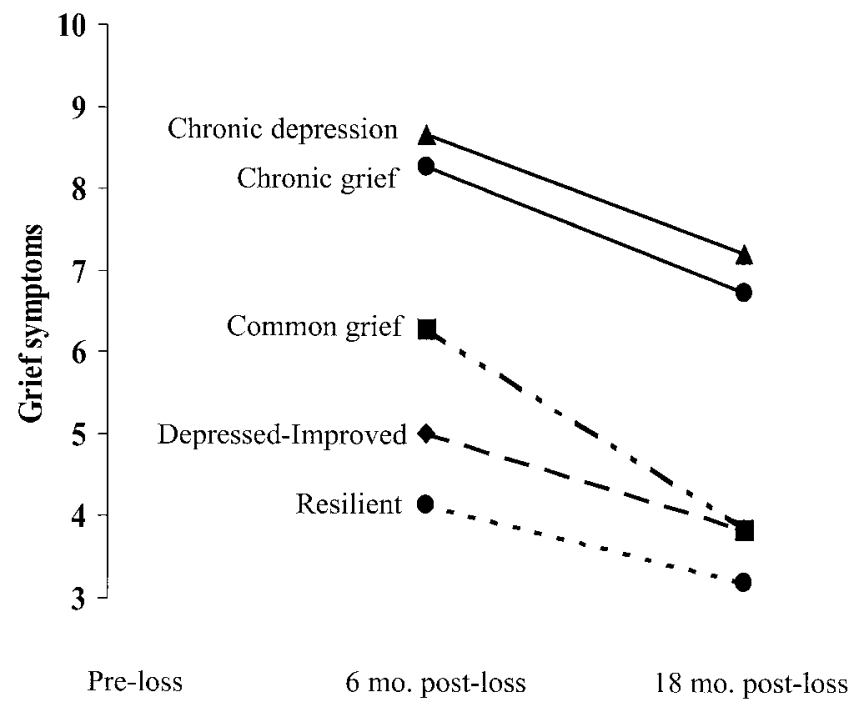

Figure 2. Total grief score for participants in each longitudinal depression pattern $(N=185)$. 


\begin{tabular}{|c|c|c|c|c|c|c|}
\hline \multirow[b]{2}{*}{ Prebereavement variable } & \multicolumn{5}{|c|}{ Bereavement pattern } & \multirow[b]{2}{*}{$F(4,80)$} \\
\hline & Resilient & $\begin{array}{l}\text { Depressed- } \\
\text { improved }\end{array}$ & $\begin{array}{c}\text { Common } \\
\text { grief }\end{array}$ & $\begin{array}{c}\text { Chronic } \\
\text { grief }\end{array}$ & $\begin{array}{l}\text { Chronic } \\
\text { depression }\end{array}$ & \\
\hline \multicolumn{7}{|l|}{ Quality of conjugal relationship } \\
\hline Positive evaluation & $-0.03(1.05)$ & $-0.77(1.42)$ & $0.07(0.62)$ & $0.13(0.73)$ & $-0.53(1.70)$ & $3.1 *_{\mathrm{dfi}}$ \\
\hline Negative evaluation & $-0.11(0.97)$ & $0.61(1.47)$ & $-0.22(1.00)$ & $-0.32(1.14)$ & $0.19(1.26)$ & $3.01 *_{d f i}$ \\
\hline Ambivalence & $0.67(1.31)$ & $1.82(2.34)$ & $0.51(1.41)$ & $0.35(0.77)$ & $1.04(2.05)$ & $3.67 * *{ }_{\mathrm{dfi}}$ \\
\hline Interpersonal dependency & $-0.11(0.89)$ & $0.09(0.96)$ & $0.14(1.13)$ & $0.31(0.88)$ & $0.71(1.02)$ & $3.30 *_{\mathrm{cgh}}$ \\
\hline Dependency on spouse & $-0.29(1.10)$ & $-0.42(1.30)$ & $0.13(0.79)$ & $0.19(0.86)$ & $0.22(0.60)$ & $2.58 * \mathrm{~cd}$ \\
\hline Avoidant/dismissive attachment & $-0.08(0.95)$ & $0.09(1.15)$ & $-0.09(1.14)$ & $-0.16(1.00)$ & $-0.14(0.84)$ & 0.28 \\
\hline \multicolumn{7}{|l|}{ Interviewer ratings } \\
\hline Interpersonal skill & $4.37(0.96)$ & $3.95(0.92)$ & $4.18(0.85)$ & $4.16(0.93)$ & $4.00(0.82)$ & 1.31 \\
\hline Interpersonal warmth & $1.46(0.98)$ & $1.38(0.50)$ & $1.41(0.51)$ & $1.39(0.56)$ & $1.38(0.50)$ & 0.11 \\
\hline Interpersonal comfort & $4.48(0.88)$ & $3.95(0.97)$ & $4.32(0.84)$ & $4.26(0.86)$ & $4.19(0.75)$ & 1.89 \\
\hline \multicolumn{7}{|l|}{ Coping resources } \\
\hline Perceived coping efficacy & $-0.07(0.96)$ & $0.22(1.25)$ & $0.10(1.11)$ & $-0.05(0.72)$ & $0.90(1.07)$ & $3.53 *_{\text {aghj }}$ \\
\hline Personal religious devotion & $0.20(1.00)$ & $0.11(0.98)$ & $0.40(0.69)$ & $-0.06(0.82)$ & $-0.12(1.18)$ & 1.26 \\
\hline Personal religious conservatism & $0.05(1.10)$ & $-0.03(0.90)$ & $-0.02(0.91)$ & $0.05(1.09)$ & $-0.16(1.06)$ & 0.16 \\
\hline Introspection & $-0.19(0.95)$ & $0.54(1.12)$ & $-0.16(0.96)$ & $-0.10(1.12)$ & $0.47(1.02)$ & $3.39 * *{ }_{\mathrm{dfi}}$ \\
\hline Extraversion & $0.29(0.95)$ & $-0.07(1.01)$ & $0.46(0.79)$ & $0.01(0.67)$ & $-0.48(0.57)$ & $4.13 * *$ \\
\hline Emotional stability & $0.27(1.03)$ & $-0.51(0.93)$ & $0.14(0.98)$ & $0.16(0.62)$ & $-0.83(0.84)$ & $6.72 * * * *_{\text {adefgij }}$ \\
\hline Conscientiousness & $0.29(0.95)$ & $-0.01(0.82)$ & $0.16(1.01)$ & $0.02(0.78)$ & $-0.29(1.01)$ & 1.88 anctgit \\
\hline Agreeableness & $0.24(1.03)$ & $0.06(1.04)$ & $0.52(1.04)$ & $0.29(0.82)$ & $0.10(0.91)$ & 0.71 \\
\hline Openness & $0.24(1.00)$ & $0.08(1.11)$ & $0.47(0.77)$ & $-0.15(1.03)$ & $-0.03(1.06)$ & 1.63 \\
\hline \multicolumn{7}{|l|}{ World view (meaning) } \\
\hline Just world & $0.21(0.96)$ & $0.06(0.84)$ & $-0.47(0.98)$ & $0.03(0.83)$ & $-0.26(1.13)$ & $3.00 *_{\mathrm{c}}$ \\
\hline Personal injustice & $-0.11(0.95)$ & $0.65(1.12)$ & $-0.37(0.87)$ & $-0.13(0.96)$ & $0.28(1.01)$ & $3.76 * *{ }_{d f i i}$ \\
\hline Uncontrollability & $-0.13(1.01)$ & $0.02(1.04)$ & $-0.21(1.22)$ & $0.20(0.84)$ & $0.52(0.72)$ & $2.00 \dagger_{\mathrm{gg}}$ \\
\hline Acceptance of death & $0.26(0.74)$ & $0.12(1.00)$ & $-0.30(0.74)$ & $-0.34(1.11)$ & $-0.15(1.13)$ & $3.99 * *_{\mathrm{ce}}$ \\
\hline \multicolumn{7}{|l|}{ Context } \\
\hline Social support: friend/relative & $0.40(0.96)$ & $-0.04(0.88)$ & $0.37(0.50)$ & $0.21(0.99)$ & $-0.08(0.77)$ & 1.34 \\
\hline Social support: children & $0.25(0.76)$ & $-0.30(1.17)$ & $0.11(0.67)$ & $0.21(0.96)$ & $0.26(0.81)$ & 1.63 \\
\hline Instrumental support & $0.22(1.00)$ & $-0.47(1.04)$ & $-0.19(0.94)$ & $-0.21(1.01)$ & $-0.35(1.13)$ & $3.17{ }^{*}{ }_{\mathrm{cfg}}$ \\
\hline
\end{tabular}

Note. Significant differences $(p<.05)$ : a $=$ chronic grief versus chronic depression; $\mathrm{c}=$ chronic grief versus resilient; $\mathrm{d}=$ chronic grief versus depressed-improved; $\mathrm{e}=$ resilient versus common grief; $\mathrm{f}=$ resilient versus depressed-improved; $\mathrm{g}=$ resilient versus chronic depression; $\mathrm{h}=$ depressed-improved versus chronic depression; $\mathrm{i}=$ depressed-improved versus common grief; $\mathrm{j}=$ chronic depression versus common grief.

$\dagger p<.10 . \quad * p<.05$. $\quad * * p<.01 . \quad * * * p<.001$.

levels of preloss depression, the chronic grief and chronic depression groups were both highly dependent, and the resilient and depressed-improved groups were both low in dependency.

The hypothesis that individuals who show the resilient pattern are actually cold, aloof, and distant was formalized into the predictions that prior to the loss the resilient group would score higher on avoidant/dismissive attachment and would be rated by interviewers as less comfortable, less skillful, and as having less warmth when interacting with others relative to chronic grievers. Group differences failed to approach significance for any of these variables.

Coping resources. The hypothesis that chronic grief results from a lack of coping resources whereas resilience is associated with more abundant coping resources was formalized into the prediction that chronic grievers would report less confidence in their own coping ability and would score lower on the personal devotion and personal conservatism dimensions of religious involvement relative to resilient individuals. Although a significant group difference was observed for coping confidence, pairwise comparisons of the chronic grief, common grief, and resilient patterns were not statistically significant. Group differences on the two religious involvement variables failed to approach significance.
Pairwise comparisons did show, however, that chronically depressed individuals had lower perceived coping ability than all other groups, including depressed-improved individuals. Thus, prior to a loss, it may be possible to predict which highly depressed respondents are likely to remain depressed by assessing perceived coping ability. Moreover, these findings help explain why, in the absence of preloss data, the clear association of chronic depression with poor perceived coping ability might be inadvertently generalized to chronic grievers.

We did not formalize specific predictions regarding group differences in personality variables, but rather conducted exploratory analyses using dimensions of the five-factor model and a measure of the disposition toward introspection. Significant group effects were evidenced for Extraversion, Neuroticism, and introspection. Although the resilient, common, and chronic grief patterns did not differ significantly on these variables, not surprisingly, both chronically depressed and depressed-improved individuals were significantly more neurotic than other participants. Depressed-improved individuals were also significantly more introspective than the resilient, common grief, and chronic grief groups. Chronically depressed individuals had the lowest Extraversion scores and were significantly lower in Extraversion than the common grief and resilient groups. The high introspection and Neuroticism among 
depressed-improved respondents helps explain how, in the absence of preloss data, these qualities may inadvertently be attributed to resilient individuals, because bereaved individuals who do not show distress are often described as maladjusted and self-absorbed.

World view. The hypothesis that resilience is associated with world views that can readily assimilate the existential threat of loss led to predictions that the resilient group would score higher on the acceptance of death and belief in a just world, and lower on the belief in personal injustice and uncontrollability of negative events relative to chronic grievers, whose world views might leave them especially vulnerable to interpersonal loss. Significant group differences were evidenced for acceptance of death, belief in a just world, and belief in personal injustice. Group differences for uncontrollability were marginally significant. Consistent with predictions, pairwise comparisons revealed that resilient individuals were significantly more accepting of death than both common grievers and chronic grievers, and endorsed significantly greater belief in a just world than common grievers. These groups did not differ significantly in belief in personal injustice or in belief in the uncontrollability of negative events. Together, these results support the hypothesis that resilient individuals have world views that help buffer the death of a spouse. However, a clear linkage between chronic grief and dysfunctional world views did not emerge.

Chronically depressed individuals scored significantly higher than resilient individuals on the belief in the uncontrollability of negative events. Depressed-improved individuals scored significantly higher than all groups except chronically depressed individuals on belief in personal injustice. Neither depressed-improved nor chronically depressed individuals were statistically different from other groups on acceptance of death and belief in a just world. These results complement those for the low preloss depression groups by linking high preloss depression with relatively negative world views.

Context. Previous studies have been inconclusive as to whether caregiving for a seriously ill spouse results in prolonged or improved depression during bereavement. To address this issue, we assigned participants to four categories on the basis of spouse health, caregiving behavior, and following Schulz, Martire, Beach, and Scheier (2001), caregiving strain. The spouses of 38 participants were healthy prior to their death, whereas 63 participants had ill spouses but did not provide direct care for their spouse prior to their death, 50 participants provided care for an ill spouse but had low caregiver strain, and 34 participants provided care for an ill spouse and experienced high caregiver strain prior to the spouse's death. A chi-square analysis of these data revealed a significant, nonrandom distribution across the five bereavement outcome patterns, $\chi^{2}(12, N=185)=28.93, p<.01$. Follow-up analyses of individual cells compared the frequency probability for each cell relative to chance using Haberman's (1978) standardized, adjusted residuals statistic (HAR). Four cells showed significant nonchance distributions. Common grievers were significantly more likely to have had a seriously ill spouse for whom they did not provide care. Whereas the chance proportion for this category was 34\%, more than half of the common grievers (12 of 22, 54.4\%) fell into this cell, HAR $=2.2, p<.05$. Depressed-improved individuals were significantly less likely to have a healthy spouse (i.e., more likely to have an ill spouse), HAR $=2.5, p<.05$. In fact, whereas the chance proportion of healthy spouses for each bereavement pattern was $21 \%$, not one of the spouses of the depressed-improved participants had been healthy prior to their death. In contrast, spouses of chronic grievers were significantly more likely to have been healthy prior to their death $(14$ of $32,43.7 \%)$, HAR $=3.6$, $p<.001$. Further, chronic grievers were significantly underrepresented in the category of high strain caregivers, HAR $=-2.4, p<$ .05 . Whereas the chance proportion for each bereavement pattern of high strain caregivers was $18 \%$, only 1 chronic griever (2\%) had provided care under high strain conditions. The spouse illness/ caregiving categories did not differentiate participants' evaluations of the positive, $F(3,181)=0.80, p=.49$, and negative, $F(3$, $181)=0.45, p=.78$, aspects of the marriage, or their level of ambivalence about the relationship, $F(3,181)=0.55, p=.65$.

An additional contextual hypothesis was that chronic grievers would report less social support from friends/relatives or children, and have less instrumental support relative to resilient individuals. Significant group differences were observed only for instrumental support. Consistent with predictions, pairwise comparisons showed that chronic grievers had significantly less instrumental support than resilient individuals. Pairwise comparisons also showed that both depressed-improved and chronically depressed individuals had less instrumental support than resilient individuals. ${ }^{4}$

\section{Discussion}

Researchers and theorists concerned with how people cope with stressful life events have had a particularly keen interest in chronic distress as well as in the absence of distress following loss. Chronic grief reactions suggest obvious clinical and social concerns. The conspicuous absence of grief has also been viewed as a maladaptive response worthy of clinical concern, but by the same token, suggests compelling parallels to other forms of resilience in the face of adversity. Unfortunately, knowledge about these types

\footnotetext{
${ }^{4}$ To determine whether the data analyses would be affected by absorbing the underrepresented patterns into the five major patterns that were identified, we ran the analyses as follows. First, we collapsed the 8 participants (3.9\% of the sample) who showed a delayed grief pattern (low prebereavement depression, no change from prebereavement to 6 months, grief reaction at 18 months) into the resilient group, which increased in size from 94 to 102. To examine whether this change in group membership altered the relationship between resilience and the prebereavement predictor variables, we recalculated the pairwise comparisons for variables that had shown significant differences between the resilient group and either common or chronic grievers. In each case, the results were virtually identical. Ten participants ( $4.9 \%$ of the sample) had shown an elevated depression from prebereavement to 6-months postloss, but improved at 18 -months postloss (depression-delayed improvement), and 2 participants ( $1.0 \%$ of the sample) had shown high prebereavement depression, improvement at 6-months postloss, and then elevated depression again at 18-months postloss (depression-improvement-relapse). Because both of these patterns could be characterized as showing some form of improved functioning during bereavement, we created a more inclusive depressionimprovement pattern that consisted of any participant with high prebereavement depression who showed improved functioning at any point during bereavement. This more inclusive definition increased the number of depressed-improved individuals from 32 to 44 . We next recalculated the pairwise comparisons between the more inclusive depressed-improved group and other participants. The results were identical to the previous analysis.
} 
of reactions and the factors that might predispose a bereaved person toward such reactions has been seriously limited by the methodological constraints of previous bereavement studies. Owing primarily to the difficulty of obtaining truly prospective data, the vast majority of studies in this area have relied on data obtained after the loss and aggregated across participants. Although an understandable compromise, this practice obscures the full course of grief reactions and confounds predictor variables with changes in perception and functioning brought about by the loss.

By using prospective data beginning prior to the death and continuing through 18 months of bereavement, we first sought to improve the operational definition of the core patterns of grief across time. This approach revealed several important findings. First, chronic grief reactions $(15.6 \%)$ could be distinguished from enduring, chronic depression (7.8\%). Second, chronic grievers could be distinguished from other participants with low preloss depression by their elevated depression and grief symptoms at 6 months of bereavement. Thus, it appears that bereaved individuals who ultimately develop chronic grief can be distinguished from other bereaved individuals even in the early months of bereavement. Third, the most frequent bereavement pattern was not the so-called common pattern of elevated depression that gradually declines over time (10.7\%), but rather the stable, low depression or resilient pattern $(45.9 \%)$. Fourth, a sizable minority of respondents $(10.2 \%)$ exhibited a pattern that had been suggested in the literature but not yet documented in a prospective study: high preloss depression followed by improvement during bereavement. Fifth, there was no clear evidence for a delayed grief pattern, thus adding to the growing number of studies that have explicitly assessed but not found evidence for delayed grief (Bonanno \& Field, 2001; Bonanno et al., 1995; Bornstein et al., 1973; Lund et al., 19851986; Middleton et al., 1996; Vachon, Sheldon, et al., 1982; Zisook \& Shuchter, 1986). As Figure 1 illustrates, without preloss data it would have been nearly impossible to distinguish these different patterns. These findings alone present a dramatic challenge to contemporary assumptions about chronic and absent grieving, and suggest that many of these assumptions may have resulted at least in part out of confusion between these different patterns.

This point was further underscored by examining the bereavement patterns in relation to preloss predictor variables. Bereavement theorists have associated chronic grief with difficulties in the conjugal relationship (e.g., conflict, ambivalence, excessive dependency), poor coping resources, beliefs or "world views" that leave people vulnerable to highly stressful events such as the death of a spouse, and a less favorable preloss context (e.g., reduced social support). Unfortunately, knowledge of these factors has derived largely from clinical observation or empirical data garnered after the loss; data sources that inextricably confound the hypothesized predisposition with current grief. Further, in the absence of preloss data, previous studies could not determine the extent that their observations applied to chronically grieved individuals or to chronically depressed individuals.

Given the seriousness of these methodological limitations, it is not surprising that when we distinguished chronic grief from chronic depression, very few of the variables hypothesized in the literature as antecedents of chronic grief reached statistical significance. The clearest predictor of chronic grief was excessive dependency, both as dependency on the spouse and as a more general personality variable. In contrast, several preloss variables assumed in the literature to underlay chronic grief were instead strongly associated with chronic depression. For instance, chronically depressed individuals had little that was positive to say about their marriages, were highly emotionally unstable, had low confidence in their own ability to cope with stressful events, and believed strongly that negative events were uncontrollable.

The prevalence of the resilient pattern in the current study attests to the importance of clarifying its preloss predictors, especially in light of the fact that many bereavement theorists have speculated about the possible unhealthy or maladaptive nature of mild or absent grief reactions (e.g., Bowlby, 1980; Rando, 1992; Worden, 1991). Jacobs (1993), for instance, concluded that bereaved individuals who experience "inhibited grief ... ought to be offered brief psychotherapy by a skilled therapist" (p. 246). One such view we examined was that individuals who fail to show overt signs of grieving were either superficially attached to their spouse (e.g., Fraley \& Shaver, 1999) or avoidant and emotionally distant (e.g., Rando, 1993). Not only did the evidence fail to support this view, there were several pieces of evidence to support the competing hypothesis that the resilient group was indeed comprised of relatively well-adjusted, resilient individuals with adequate coping resources. Further, as in the confusion between chronic grief and chronic depression, the maladaptive profile assumed to underlie absent grief was instead associated with the depressed-improved group. Depressed-improved participants appeared to be relatively maladjusted and self-absorbed and to have inadequate coping resources to deal with their stress. They were relatively negative and ambivalent about their marriages, more likely to have a spouse who was seriously ill, had the lowest levels of instrumental support, were highly introspective and emotionally unstable, and believed strongly that the world was particularly unjust to them.

Despite the methodological advantages inherent in the current study, there were three important limitations that warrant discussion. First, the data were garnered solely from participant selfreports and from interviewer observations. It will be important to determine whether these findings hold when more objective indicators of behaviors and health are used. ${ }^{5}$ A second limitation is that the data covered only 18 months of bereavement. Although bereavement studies have rarely collected data beyond 2 years postloss, the measurement of functioning beyond this point becomes particularly relevant to questions of resilience and possible delayed grief. In the absence of more extended longitudinal data, we cannot fully rule out the possibility that resilient participants may eventually exhibit delayed manifestations of grief. However, a recent study that followed conjugally bereaved participants for 5 years after the death of their spouse suggests this is not a likely scenario (Bonanno \& Field, 2001).

A third methodological consideration concerns the generalizability of the present findings. The mean age of the current sample (72 years) raises important concerns as to whether similar findings would be evident among younger individuals. Although this issue cannot be addressed directly by these data, it does appear that the

\footnotetext{
${ }^{5}$ Although a variety of objective indicators were obtained in the present study (e.g., blood and urine samples, measures of cognitive functioning), the expense of obtaining data of this sort necessitated that they were collected only from a subsample of the respondents. Focusing solely on that subsample would not have afforded sufficient statistical power to conduct the analyses necessary for this article.
} 
basic patterns of grief course were quite similar to those observed in a range of other bereavement studies. Specifically, the proportions of participants in the present study showing either the resilient or chronic grief patterns (see Figure 1) are well within the range observed in previous studies (Bonanno \& Kaltman, 2001). There is less room for confidence, however, in generalizing from the current findings on preloss predictors of these patterns. Indeed, a number of the variables we examined are particularly relevant to older samples (e.g., caregiving, instrumental support) and may be less crucial in the coping process of younger bereaved individuals. Similarly, it would be particularly interesting to know whether these patterns hold for the younger bereaved, whose spouse's death is often sudden, untimely, and occurs under traumatic circumstances (i.e., motor vehicle crash or homicide). On the basis of past literature (e.g., Bonanno \& Kaltman, 1999; Lehman et al., 1987), we anticipate that a greater percentage of younger respondents would exhibit chronic grief.

Our results have important implications both for the bereavement literature and for more general theories of personality and life stress. One implication pertains to the treatment of bereaved individuals. Previous studies have suggested that the evidence for the efficacy of bereavement interventions is at best mixed. In fact, in a recent meta-analysis, Fortner, Neimeyer, Anderson, and Berman (reported in Neimeyer, 2000) found that grief treatments produced only a small positive effect, and that an alarming $38 \%$ of those receiving grief treatment actually got worse relative to notreatment controls. However, follow-up analyses indicated that interventions were relatively more effective when individuals were preselected for complicated grief. Although chronically grieved individuals were a relatively small group in this and previous research, these data do appear to confirm that they are most in need of intervention.

Even though grief treatments worked best for chronically grieved individuals, their effectiveness for these individuals is still modest compared with that generally observed for psychotherapy (Neimeyer, 2000). The predictor variables in the present study that most reliably distinguished the chronic grief group were excessive dependency, low instrumental support, and greater likelihood of having a healthy spouse. Chronic grievers' dependency on their spouses suggests that they should indeed benefit at least to some extent from the traditional emphasis on working through the lost relationship (Rando, 1993; Worden, 1991). However, because chronic grievers also scored highly on the trait dependency measure, therapy might also focus on helping them develop a broader and more functional sense of independence in other relationships beyond the lost conjugal relationship (Bonanno et al., in press: Davis et al., 2000). Further, the findings that chronic grievers were most likely to have lost a healthy spouse and had relatively low levels of instrumental support suggests that they may also need help adjusting to the pragmatic realities of getting through daily life without their spouse. By the same token, the differentiation of chronic grief from chronic depression, achieved in the current study, resonates with Zisook and Shuchter's (2001) suggestion that chronically depressed individuals might benefit more from pharmacologic interventions, whereas those struggling with chronic grief may benefit more from cognitive and behavioral interventions.

Our findings regarding preloss differences among the resilient and depressed-improved groups also have implications for intervention. Indeed, the relatively little depression these groups showed during bereavement may help explain why so many bereaved individuals become worse following grief counseling. We found no evidence in our analyses to support the widely held assumption that the resilient group was actually comprised of maladjusted individuals. Offering treatment to individuals who are coping effectively is not likely to be helpful and might produce some harm by causing them to focus on issues they had already dealt with or by undermining their natural coping strategies (Bonanno et al., in press). By contrast, depressed-improved individuals showed a relatively dysfunctional profile prior to the death of their spouse that suggests more legitimate possibilities for psychotherapy. However, it is still an empirical question as to whether these individuals would benefit from a specific focus on bereavement.

The current findings suggest several implications for future research on resilience. Given the prevalence of the resilient pattern in the current study, it will be important to understand how resilient individuals are able to assimilate the loss so quickly and how these individuals might compare with resilient individuals following other types of life stress. The findings that resilient individuals are more accepting of death and believe more clearly that the world is just suggest several possible avenues. There is general agreement that stressful life events, including interpersonal loss, are likely to cause long-term difficulties if they shatter a person's views of the world (e.g. Davis et al., 2000; JanoffBulman, 1992; Parkes, 1971). However, researchers rarely have the opportunity to assess world views prior to the stressor event. The present data indicate that preloss world views play an important role in both adaptive and maladaptive processes of coping with loss. Taken together, these results suggest that more research should be focused on the protective effects of particular views of the world. Other issues of interest include identifying the antecedents of particular world views, as well as determining the stability of world views over time and their relation to other personality dimensions, how world views vary across cultures, and the extent to which world views are changed by major life events.

We have focused solely on identifying the preloss antecedents of different patterns of grieving. However, it is also important to determine whether there are differences in how individuals in the various groups react to and process the loss. For instance, one of the most important factors to emerge in recent research pertains to coping and emotion regulation processes during bereavement (Bonanno \& Kaltman, 1999). Regarding qualities of the lost relationship, we might ask whether those in the resilient group would show a greater predominance of positive, as opposed to negative, memories, as time passes? Or are they likely to show relatively few positive or negative memories? We are in the process of addressing these issues, which should add depth and richness to our understanding of the patterns of grieving.

Perhaps the most important contribution of the current research is that we were able to map the core trajectories of grief reaction in a manner that had not been possible in previous studies. This advance made it possible to test a number of speculative hypotheses in the bereavement literature and also paves the way for more systematic comparisons across life stressors. For example, bereavement is often viewed as similar to other marital transitions, such as divorce (e.g., Bowlby, 1980; Weiss, 1975). However, whereas bereavement shows a clear, direct impact on adjustment, divorce appears to exert a more indirect impact that is mediated by the additional, ongoing stressors accompanying the break-up (e.g., 
Pillow et al., 1996). This difference raises important questions about whether the same type of outcome trajectories evidenced during bereavement would be evidenced following divorce, and whether similar pre-event variables would predict these trajectories. Likewise, our delineation of a relatively unstudied group of individuals resilient to loss begs questions about the prevalence of resilience in response to other types of stressor events.

Finally, the wide range of grief patterns demonstrated in the present study suggests a need to reevaluate common notions about what constitutes a normal response to a major loss. Of course, views about normal grieving are not only prevalent among researchers and health care providers (e.g., Middleton et al., 1993), but also among lay people and the bereaved themselves. Because they are unaware of the striking variability in response to loss, potential supporters are often critical or judgmental of bereaved individuals who show too much or too little grief (Lehman, Ellard, \& Wortman, 1986; Wortman, Battle, \& Lemkau, 1997). For example, a man who begins dating 6 months after the death of his wife may elicit severe criticism from friends and neighbors who believe that such behavior indicates that the man is either shallow and superficial, or running away from his distress (Bonanno \& Keltner, 1997). The bereaved themselves might become concerned that their reaction to the loss is "abnormal" and this may add to the distress from the loss itself. Educating the bereaved, as well as their potential support providers, about the diverse forms that grief may take should be an important national priority.

\section{References}

Aldenderfer, M. S., \& Blashfield, R. K. (1984). Cluster analysis. Beverly Hills, CA: Sage.

Bass, D. M., Bowman, K., \& Noelker, L. S. (1991). The influence of caregiving and bereavement support on adjusting to an older relative's death. Gerontologist, 31, 32-42.

Bodnar, J. C., \& Kiecolt-Glaser, J. K. (1994). Caregiver depression after bereavement: Chronic stress isn't over when it's over. Psychology and Aging, 9, 372-380.

Bonanno, G. A., \& Field, N. P. (2001). Evaluating the delayed grief hypothesis across 5 years of bereavement. American Behavioral Scientist, 44, 798-816.

Bonanno, G. A., Field, N. P., Kovacevic, A., \& Kaltman, S. (2002). Self-enhancement as a buffer against extreme adversity: Civil war in Bosnia and traumatic loss in the United States. Personality and Social Psychology Bulletin, 28, 184-196.

Bonanno, G. A., \& Kaltman, S. (1999). Toward an integrative perspective on bereavement. Psychological Bulletin, 125, 760-776.

Bonanno, G. A., \& Kaltman, S. (2001). The varieties of grief experience. Clinical Psychology Review, 20, 1-30.

Bonanno, G. A., \& Keltner, D. (1997). Facial expressions of emotion and the course of conjugal bereavement. Journal of Abnormal Psychology, 106, 126-137.

Bonanno, G. A., Keltner, D., Holen, A., \& Horowitz, M. J. (1995). When avoiding unpleasant emotion might not be such a bad thing: Verbalautonomic response dissociation and midlife conjugal bereavement. Journal of Personality and Social Psychology, 46, 975-989.

Bonanno, G. A., Notarius, C. I., Gunzerath, L., Keltner, D., \& Horowitz, M. J. (1998). Interpersonal ambivalence, perceived dyadic adjustment, and conjugal loss. Journal of Consulting and Clinical Psychology, 66, 1012-1022.

Bonanno, G. A., Papa, A., \& O'Neill, K. (in press). Loss and human resilience. Applied and Preventative Psychology.

Bournstein, P. E., Clayton, P. J., Halikas, J. A., Maurice, W. L., \& Robins,
E. (1973). The depression of widowhood after thirteen months. British Journal of Psychiatry, 122, 561-566.

Bowlby, J. (1980). Loss: Sadness and depression (attachment and loss, Vol. 3). New York: Basic Books.

Boyd, J. H., Weissman, M. M., Thompson, W., Myers, D., \& Jerome, K. (1982). Screening for depression in a community sample: Understanding the discrepancies between depression syndrome and diagnostic scales. Archives of General Psychiatry, 39, 1195-1200.

Brennan, K., \& Shaver, P. R. (1998). Attachment styles and personality disorders: Their connections to each other and to parental divorce, parental death, and perceptions of parental caregiving. Journal of Personality, 66, 835-878.

Bruce, M. L., Kim, K., Leaf, P. J., \& Jacobs, S. (1990). Depressive episodes and dysphoria resulting from conjugal bereavement in a prospective community sample. American Journal of Psychiatry, 147, 608611.

Carr, D., House, J., Nesse, R. M., Sonnega, J., \& Wortman, C. B. (in press). Forewarning of spouse's death and psychological well-being of elderly widowed men and women. Journal of Gerontology.

Clark, D. M., \& Teasdale, J. D. (1982). Diurnal variation in clinical depression and accessibility of memories of positive and negative experiences. Journal of Abnormal Psychology, 91, 87-95.

Cleiren, M. P. H. D. (1993). Bereavement and adaptation: A comparative study of the aftermath of death. Philadelphia: Hemisphere Publication Services.

Cohen, D., \& Eisdorfer, C. (1988). Depression in family members caring for a relative with Alzheimer's disease. Journal of the American Geriatrics Society, 36, 885-889.

Comstock, G. W., \& Helsing, K. J. (1976). Symptoms of depression in two communities. Psychological Medicine, 6, 551-563.

Costa, P. T., \& McCrae, R. R. (1992). Normal personality assessment in clinical practice: The NEO Personality Inventory. Psychological Assessment, 4, 5-13.

Davis, C. G., \& Nolen-Hoeksema, S. (2001). Loss and meaning: How do people make sense of loss? American Behavioral Scientist, 44, 718-735.

Davis, C. G., Wortman, C. B., Lehman, D. R., \& Silver, R. C. (2000). Searching for meaning in loss: Are clinical assumptions correct? Death Studies, 24, 497-540.

Deutsch, H. (1937). Absence of grief. Psychoanalytic Quarterly, 6, 12-22.

Diener, E., Gohm, C. L., Suh, E., \& Oishi, S. (2000). Similarity of the relations between marital status and subjective well-being across cultures. Journal of Cross-Cultural Psychology, 31, 419-436.

Downey, G., Silver, R. C., \& Wortman, C. B. (1990). Reconsidering the attribution-adjustment relation following a major negative event: Coping with the loss of a child. Journal of Personality and Social Psychology, 59, 925-940.

Elliot, C. L., \& Greene, R. L. (1992). Clinical depression and implicit memory. Journal of Abnormal Psychology, 101, 572-574.

Folkman, S., Chesney, M., Collette, L., Bocellari, A., \& Cooke, M. (1996). Postbereavement depressive mood and its prebereavement predictors in HIV + and HIV - gay men. Journal of Personality and Social Psychology, 70, 336-348.

Fraley, R. C., \& Shaver, P. R. (1999). Loss and bereavement: Bowlby's theory and recent controversies concerning "grief work" and the nature of detachment. In J. Cassidy \& P. R. Shaver (Eds.), Handbook of attachment theory and research: Theory, research, and clinical applications (pp. 735-759). New York: Guilford Press.

Frederick, S., \& Loewenstein, G. (1999). Hedonic adaptation. In D. Kahneman, E. Diener, \& N. Schwarz (Eds.), Well-being: The foundations of hedonic psychology (pp. 301-329). New York: Russell Sage Foundation.

Haberman, S. J. (1978). Analysis of qualitative data. New York: Academic Press.

Harvey, J. H., \& Miller, E. D. (1998). Toward a psychology of loss. Psychological Science, 9, 429-434. 
Hirschfeld, R. M. A. (1977). A measure of interpersonal dependency. Journal of Personality Assessment, 41, 610-618.

Hirschfeld, R. M. A., Klerman, G. L., Lavori, P., Keller, M. B., Griffith, P., \& Coryell, W. (1989). Premorbid personality assessments of first onset of major depression. Archives of General Psychiatry, 46, 345-350.

Holmes, T., \& Rahe, R. (1967). The social readjustment scale. Journal of Psychosomatic Research, 11, 213-218.

Horowitz, A. (1985). Sons and daughters as caregivers to older parents: Differences in role performance and consequences. Gerontologist, 25, 612-617.

Horowitz, M. J. (1990). A model of mourning: Change in schemas of self and other. Journal of the American Psychoanalytic Association, 38, 297-324.

Horowitz, M. J., Bonanno, G. A., \& Holen, A. (1993). Pathologic grief: Diagnosis and explanation. Psychosomatic Medicine, 55, 260-273.

Jacobs, S. (1993). Pathologic grief: Maladaptation to loss. Washington, DC: American Psychiatric Press.

Jacobs, S., Kasl, S., \& Ostfeld, A. (1986). The measurement of grief: Bereaved versus non-bereaved. The Hospice Journal, 2, 21-36.

Janoff-Bulman, R. (1992). Shattered assumptions: Towards a new psychology of trauma. New York: Free Press.

Kaplan, K. J. (1972). On the ambivalence-indifference problem in attitude theory and measurement: A suggested modification of the semantic differential technique. Psychological Bulletin, 77, 361-372.

Kendler, K. S., Gardner, C. O., \& Prescot, C. A. (1997). Religion, psychopathology, and substance use and abuse: A multimeasure, geneticepidemiologic study. American Journal of Psychiatry, 154, 322-329.

Kim, K., \& Jacobs, S. (1991). Pathologic grief and its relationship to other psychiatric disorders. Journal of Affective Disorders, 21, 257-263.

Kohut, F. J., Berkman, L. E., Evans, D. A., \& Cornoni-Huntley, J. (1993). Two shorter forms of the CES-D Depression Symptoms Index. Journal of Aging and Health, 5, 179-193.

Lehman, D. R., Ellard, J. H., \& Wortman, C. B. (1986). Social support for the bereaved: Recipients' and providers' perspectives on what is helpful. Journal of Consulting and Clinical Psychology, 54, 438-446.

Lehman, D. R., Wortman, C. B., \& Williams, A. F. (1987). Long-term effects of losing a spouse or child in a motor vehicle crash. Journal of Personality and Social Psychology, 52, 218-231.

Levy, L. H., Martinkowski, K. S., \& Derby, J. F. (1994). Differences in patterns of adaptation in conjugal bereavement: Their sources and potential significance. Omega: Journal of Death \& Dying, 29, 71-87.

Lindemann, E. (1944). Symptomatology and management of acute grief. American Journal of Psychiatry, 101, 1141-1148.

Lopata, H. Z. (1979). Women as widows: Support systems. New York: Elsevier.

Lund, D. A., Dimond, M. F., Caserta, M. S., Johnson, R. J., Poulton, J. L., \& Connelly, J. R. (1985-1986). Identifying elderly with coping difficulties after two years of bereavement. Omega, 16, 213-224.

Luthar, S. S., \& Cicchetti, D. (2001). The construct of resilience: Implications for interventions and social policies. Development and Psychopathology, 12, 857-885.

McIntosh, D., Silver, R. C., \& Wortman, C. B. (1993). Religion's role in adjustment to a negative life event: Coping with the loss of a child. Journal of Personality and Social Psychology, 65, 812-821.

Middleton, W., Burnett, P., Raphael, B., \& Martinek, N. (1996). The bereavement response: A cluster analysis. British Journal of Psychiatry, 169, 167-171.

Middleton, W., Moylan, A., Raphael, B., Burnett, P., \& Martinek, N. (1993). An international perspective on bereavement related concepts. Australian and New Zealand Journal of Psychiatry, 27, 457-463.

Miller, L., Davies, M., \& Greenwald, S. (2000). Religiosity and substance use and abuse among adolescents in the national comorbidity study. Journal of the American Academy of Child and Adolescent Psychiatry, 39, 1190-1197.

Myers, D., \& Weissman, M. M. (1980). Use of a self-report symptom scale to detect depression in a community sample. American Journal of Psychiatry, 137, 1081-1084.

Neimeyer, R. A. (2000). Searching for the meaning of meaning: Grief therapy and the process of reconstruction. Death Studies, 24, 541-558.

Neimeyer, R. A., \& Levitt, H. (2001). Coping and coherence: A narrative perspective on resilience. In S. Snyder (Ed.), Coping with stress (pp. 47-67). New York: Oxford University Press.

Nolen-Hoeksema, S., \& Larson, J. (1999). Coping with loss. Mahwah, NJ: Erlbaum.

Norris, F. H., \& Murrell, S. A. (1990). Social support, life events, and stress as modifiers to bereavement by older adults. Psychology of Aging, 5, 429-436.

Nuss, W. S., \& Zubenko, G. S. (1992). Correlates of persistent depressive symptoms in widows. American Journal of Psychiatry, 149, 346-351.

Osterweis, M., Solomon, F., \& Green, F. (1984). Bereavement: Reactions, consequences, and care. Washington, DC: National Academy Press.

Parkes, C. M. (1971). Psycho-social transitions: A field for study. Social Science and Medicine, 5, 101-115.

Parkes, C. M. (1998). Bereavement: Studies of grief in adult life (3rd ed.). Madison, CT: International Universities Press.

Parkes, C. M., \& Weiss, R. S. (1983). Recovery from bereavement. New York: Basic Books

Pillow, D. R., Zautra, A. J., \& Sandler, I. N. (1996). Major life events and minor stressors: Identifying mediational links in the stress process. Journal of Personality and Social Psychology, 70, 381-394.

Prigerson, H. G., Shear, M. K., Frank, E., \& Beery, L. C. (1997). Traumatic grief: A case of loss-induced trauma. American Journal of Psychiatry, 154, 1003-1009.

Radloff, L. (1977). The CES-D scale: A self-report depression scale for research in the general population. Applied Psychological Measurement, 1, 381-401.

Rando, T. A. (1988). Anticipatory grief: The term is a misnomer but the phenomenon exists. Journal of Palliative Care, 4, 70-73.

Rando, T. (1992), The increasing prevalence of complicated mourning: The onslaught is just beginning. Omega, 26, 43-59.

Rando, T. A. (1993). Treatment of complicated mourning. Champaign, IL: Research Press.

Raphael, B. (1983). The anatomy of bereavement. New York: Basic Books.

Roberts, R. E., Rhoades, H. M., \& Vernon, S. W. (1990). Using the CES-D scale to screen for depression and anxiety: Effects of language and ethnic status. Psychiatric Research, 31, 69-83.

Sable, P. (1989). Attachment, anxiety, and loss of a husband. American Journal of Orthopsychiatry, 59, 550-556.

Safer, M. A., Bonanno, G. A., \& Field, N. P. (2001). It was never that bad: Biased recall of grief and long-term adjustment to the death of a spouse. Memory, 9, 195-204.

Sanders, C. M. (1993). Risk factors in bereavement outcome. In M. S. Stroebe, W. Stroebe, \& R. O. Hansson (Eds.), Handbook of bereavement: Theory, research, and intervention (pp. 255-270). Cambridge, England: Cambridge University Press.

Schrader, G., Davis, A., Stefanovic, S., \& Christie, P. (1990). The recollection of affect. Psychological Medicine, 20, 105-109.

Schulz, R., Martire, L. M., Beach, S. R., \& Scheier, M. F. (2001). Depression and mortality in the elderly. Current Directions in Psychological Science, 9, 204-209.

Schwartzberg, S. S., \& Janoff-Bulman, R. (1991). Grief and the search for meaning: Exploring the assumptive worlds of bereaved college students. Journal of Social and Clinical Psychology, 10, 270-288.

Scott, W. A. (1966). Measures of cognitive structure. Multivariate Behavioral Research, 1, 391-395.

Shaver, P. R., \& Tancredy, C. M. (2001). Emotion, attachment, and bereavement: A conceptual commentary. In M. S. Stroebe, R. O. Hansson, W. Stroebe, \& H. Schut (Eds.), Handbook of bereavement research (pp. 63-88). Washington, DC: American Psychological Association.

Shuchter, S. R., \& Zisook, S. (1993). The course of normal grief. In M. S. 
Stroebe, W. Stroebe, \& R. O. Hansson (Eds.), Handbook of bereavement: Theory, research, and intervention (pp. 23-43). Cambridge, England: Cambridge University Press.

Simpson, J. A. (1990). Influence of attachment styles on romantic relationships. Journal of Personality and Social Psychology, 59, 971-980.

Singh, B., \& Raphael, B. (1981). Postdisaster morbidity of the bereaved: A possible role for preventive psychiatry? The Journal of Nervous and Mental Disease, 169, 203-212.

Spanier, G. B. (1976). Measuring dyadic adjustment: New scales for assessing the quality of marriage and similar dyads. Journal of Marriage and the Family, 38, 15-28.

Stroebe, M. S., Hansson, R. O., \& Stroebe, W. (1993). Contemporary themes and controversies in bereavement research. In M. S. Stroebe, W. Stroebe, \& R. O. Hansson (Eds.), Handbook of bereavement: Theory, research, and intervention (pp. 457-476). Cambridge, England: Cambridge University Press.

Stroebe, M. S., \& Schut, H. (2001). Risk factors in bereavement outcome: A methodological and empirical review. In M. S. Stroebe, R. O. Hansson, W. Stroebe, \& H. Schut (Eds.), Handbook of bereavement research (pp. 349-372). Washington, DC: American Psychological Association.

Stroebe, W., \& Stroebe, M. S. (1987). Bereavement and health. New York: Cambridge University Press.

Stroebe, W., \& Stroebe, M. S. (1993). Determinants of adjustment to bereavement in younger widows and widowers. In M. S. Stroebe, W. Stroebe, \& R. O. Hansson (Eds.), Handbook of bereavement (pp. 208226). New York: Cambridge University Press.

Thompson, M. M., \& Zanna, M. P. (1995). The conflict individual: Personality-based and domain-specific antecedents of ambivalent social attitudes. Journal of Personality, 63, 259-288.

Vachon, M. L. S., Rogers, J., Lyall, W. A., Lancee, W. J., Sheldon, A. R., \& Freeman, S. J. J. (1982). Predictors and correlates of adaptation to conjugal bereavement. American Journal of Psychiatry, 139, 998-1002.

Vachon, M. L. S., Sheldon, A. R., Lancee, W. J., Lyall, W. A. L., Rogers, J., \& Freeman, S. J. J. (1982). Correlates of enduring distress patterns following bereavement: Social network, life situation and personality. Psychological Medicine, 12, 783-788.

Vinokur, A. D., Brown, S. L., Carr, D., Nesse, R. M., Sonnega, J., \& Wortman, C. B. (2002). The structure and predictors of grief reactions: A prospective study of older widowed adults. Manuscript submitted for publication

Wallace, K. A., Bisconti, T. L., \& Bergeman, C. S. (2001). The mediational effect of hardiness on social support and optimal outcomes in later life. Basic and Applied Social Psychology, 23, 267-279.

Waysman, M., Schwarzwald, J., \& Solomon, Z. (2002). Hardiness: An examination of its relationship with positive and negative long term changes following trauma. Journal of Traumatic Stress, 14, 531-548.

Weiss, R. S. (1975). Marital separation. New York: Basic Books.

Wheaton, B. (1990). Life transitions, role histories, and mental health. American Sociological Review, 55, 209-223.

Worden, J. W. (1991). Grief counseling and grief therapy: A handbook for the mental health practitioner (2nd ed.). New York: Springer Publishing Company.

Wortman, C. B., Battle, E. S., \& Lemkau, J. P. (1997). Coming to terms with the sudden, traumatic death of a spouse or child. In R. C. Davis \& A. J. Lurigio (Eds.), Victims of crime (2nd ed., pp. 108-133). Thousand Oaks, CA: Sage.

Wortman, C. B., \& Silver, R. C. (1989). The myths of coping with loss. Journal of Consulting and Clinical Psychology, 57, 349-357.

Wortman, C. B., \& Silver, R. C. (2001). The myths of coping with loss revisited. In M. S. Stroebe, R. O. Hansson, W. Stroebe, \& H. Schut (Eds.), Handbook of bereavement research: Consequences, coping, and care (pp. 405-430). Washington, DC: American Psychological Association.

Zimmerman, M., \& Coryell, W. (1986). Reliability of follow-up assessments of depressed inpatients. Archives of General Psychology, 43, 468-470.

Zisook, S., DeVaul, R. A., \& Click, Jr. M. A. (1982). Measuring symptoms of grief and bereavement. American Journal of Psychiatry, 139,15901593.

Zisook, S., Paulus, M., Shuchter, S. R., \& Judd, L. L. (1997). The many faces of depression following spousal bereavement. Journal of Affective Disorders, 45, 85-94.

Zisook, S., \& Shuchter, S. R. (1986). The first four years of widowhood. Psychiatric Annals, 16, 288-294.

Zisook, S., \& Shuchter, S. R. (1991). Depression through the first year after the death of a spouse. American Journal of Psychiatry, 148, 1346-1352.

Zisook, S., \& Shuchter, S. R. (2001). Treatment of depressions of bereavement. American Behavioral Scientist, 44, 782-798.

Received December 3, 2001 Revision received April 15, 2002 Accepted April 16, 2002 